\title{
COMPARISON OF TEAR FILM THICKNESS IN THREE SPECIES DETERMINED BY THE GLASS FIBRE METHOD AND CONFOCAL MICROSCOPY
}

\author{
J. I. PRYDAL ${ }^{1}$, M. G. KERR MUIR ${ }^{1}$ and P. N. DILLY ${ }^{2}$ \\ London
}

\begin{abstract}
SUMMARY
Using optical methods to measure tear film thickness we previously found that values were substantially larger than earlier estimates by mechanical and chemical techniques. The predominant component was found to be mucus, not aqueous fluid. This article describes the results of using confocal microscopy to re-examine an earlier method of measuring thickness, the glass fibre technique. Confocal microscopy enabled visual identification of tear and epithelial surfaces and accurate measurement of the separation between them, giving the full film thickness. Consecutive measurements were made by each method in eyes of 22 animals of three species. Measurements using fibres in rabbits gave results of $7 \mu \mathrm{m}$, replicating earlier findings. However, the fibre technique gave the same result in all species. Values were not correlated with measurements by microscopy, which ranged from 10 to $14 \mu \mathrm{m}$. We propose that fibres were too flexible to be pressed through all mucus layers and contact epithelium, and as a result this method underestimated film thickness.
\end{abstract}

We previously reported measurements of tear film thickness in humans ${ }^{1}$ and several animal species ${ }^{2}$ using two independent optical techniques: laser interferometry and confocal microscopy. Animals were examined very shortly after death, and under such conditions eyes were immobile and confocal microscopy enabled direct visual identification and localisation of tear film and epithelial surfaces. The separation between them was the full tear film thickness. It was accurately measured using the stage micrometer of the microscope. Consecutive measurements by the two methods in the same eyes were closely correlated in all animals, indicating that results were valid. Thickness ranged from $9 \mu \mathrm{m}$ in frog to $15 \mu \mathrm{m}$ in gerbil. No tear film was detected in two species of freshwater fish.

From: 'Department of Ophthalmology, St. Thomas' Hospital, London; '2Department of Anatomy, St. George's Hospital Medical School, London, UK.

Correspondence to: J. I. Prydal, Department of Ophthalmology, St. Thomas' Hospital, Lambeth Palace Road, London SE1 7EH, UK.
These values are substantially larger than the earlier measurements by mechanical and chemical methods of 4-7 $\mu \mathrm{m}$ in rabbit ${ }^{3}$ and man. ${ }^{4,5}$ Interferometry of human eyes gave values of about $40 \mu \mathrm{m}$, which is more than four times thicker than the earlier estimates. Accurate measurements by confocal microscopy were not possible because of involuntary eye movements, but they provided supportive evidence of measurements by interferometry.

The structure of the tear film was also found to be different from earlier descriptions. Wolff, ${ }^{6}$ in 1946, proposed that the film consisted of three layers: (1) a lipid layer at the air interface, (2) a middle aqueous layer, and (3) a mucous layer on the epithelium. McDonald ${ }^{7}$ measured lipid thickness in human eyes to be less than $0.1 \mu \mathrm{m}$ using colours of interference patterns formed in reflected white light. Mucus thickness in guinea pig eyes was measured by Nicholls et al. ${ }^{8}$ to be $1 \mu \mathrm{m}$ using electron microscopy of frozen sections. These findings supported a view that the film is a three-layered structure in which the main component is free aqueous fluid. In our own earlier studies ${ }^{1,2}$ we estimated mucus content in rat and human eyes by measuring the reduction in thickness after application of a mucolytic agent. Substantial thinning indicated that the film was composed largely of mucus, not aqueous fluid.

In the work presented here we examined one of the earlier mechanical methods for measurement of tear film thickness. Mishima ${ }^{3}$ laid fine glass fibres of known diameter in the tear film of anaesthetised rabbits. The eye surface was viewed with a slit lamp, and fibres pressed into the film. Thickness was taken to be the diameter of fibre that appeared level with the surface: about $7.5 \mu \mathrm{m}$. This was an apparently simple, direct observation. However, it is evident that there is an underlying assumption that these fibres occupy the tear film space fully. One of the results of our earlier work was that there was in fact a much thicker layer of mucus than had been appreciated. If glass fibres do not occupy the full thickness between epithelium and external film surface, measurements will be less than the space available. Also pressure on mucus may express fluid 
and change the structure being measured. Advantages of the optical methods were that they caused minimal, if any, alteration to the film and also measurements were of full film thickness. Confocal microscopy gave clear images of epithelium and external tear surfaces and made possible measurement of the separation between them. Close agreement with measurements by interferometry indicated that this method also included all mucus layers.

In the present studies consecutive measurements were made in the same eyes, first using glass fibres and then confocal microscopy. Attempts were made to replicate earlier findings in rabbit eyes and measurements were extended to two other species, selected to have a range of film thickness. ${ }^{2}$ Confocal microscopy was used to visualise the portion of film thickness occupied by a fibre that appeared level with the surface.

\section{MATERIALS AND METHODS}

\section{Glass Fibre Method}

Fibres were drawn from Pyrex rods, and $1 \mathrm{~cm}$ lengths cemented to ends of matchsticks. Their diameter was measured using a microscope with calibrated graticule (resolution $0.5 \mu \mathrm{m}$ ) at $\times 450$ magnification. Fourteen fibres were prepared, from 3 to $20 \mu \mathrm{m}$ in steps of less than 1.5 $\mu \mathrm{m}$. Care was taken to exclude tapered fibres (e.g. one of diameter $7 \mu \mathrm{m}$ narrowed by less than $1 \mu \mathrm{m}$ over $3 \mathrm{~mm}$ ). Measurements were made using the length of fibre 1-2 $\mathrm{mm}$ from its tip.

The eye surface was viewed with a dissecting microscope, magnification $\times 40$, and measurements made in the centre of the cornea. Fibres of increasing diameter were rested on eyes and as much pressure as possible applied towards the eye. Successively larger fibres were used until one appeared level with, or protruded from, the surface. If two consecutive sizes looked equally level with the surface, or if one fibre did not protrude and the next size up did, the average of their diameters was taken to be the measurement. The procedure was repeated using two fibres of smaller diameter, and two of larger diameter, to confirm the reading.

\section{Confocal Microscopy}

Confocal microscopy is a significant modification of scanning reflected light microscopy. Images are high-resolution, thin 'optical sections' through specimens ${ }^{9,10}$ and this enables structures deep in tissues to be imaged without fixation or staining.

Measurement of film thickness using confocal microscopy was described in our earlier work. ${ }^{2}$ Examination of eyes required oil immersion to reduce reflections from the tear film surface and give identifiable images of epithelium. There was no evidence from our earlier work to indicate that application of oil changed film thickness. A $\times 40$ immersion objective (Zeiss Plan Apochromat, NA 1.0) was used with $\times 10$ eyepiece and Zeiss $518 \mathrm{C}$ immersion oil $(n=1.515)$. Eye position was adjusted so that images were circular. Optical sections were then tangential to surfaces and measurements were of radial thickness. Sections were 1-2 $\mu \mathrm{m}$ thick and surfaces could be precisely located. Ten measurements of the separation between epithelial and tear film surfaces were made using the microscope fine focus. The focussing mechanism was calibrated using eight sheets of polyester ester (Goodfellow Metals, $n=1.65$ ) or polyethylene teraphthalate (Film Sales, $n=1.65$ ) from 6 to $120 \mu \mathrm{m}$. Their thickness was measured using a microscope (up to $\times 450$ magnification) with calibrated graticule of resolution $0.5 \mu \mathrm{m}$.

The equation relating thickness to graduations of fine focus was determined by linear regression analysis:

$$
t=0.581+1.041 g
$$

where $t$ is thickness and $g$ the graduations of fine focus. The correlation coefficient was 0.997 and confidence limits at thickness $12 \mu \mathrm{m}$ were $\pm 1.8 \mu \mathrm{m}$. Thus the method of calibration was sufficiently accurate for measurement of tear film thickness. Thickness calculated from this equation was corrected for the different refractive indices of tear fluid $(1.337)^{11}$ and calibration materials. $^{2}$

\section{PROCEDURE}

\section{Measurements Using Glass Fibres and Confocal Microscopy}

Consecutive measurements by the two methods were made in the centre of the cornea of the same eye. Animals were examined as soon as possible after death, with the eye undisturbed in the orbit. Measurements with fibres were made within 1-5 minutes of death, and by confocal microscopy within 5-12 minutes. This sequence was necessary because microscopy was done with oil, which would have altered measurements using glass fibres. One eye each of 8 rabbits, 8 rats and 6 pigeons were examined. Details about the species studied are given in Table I. Eyes of pigeons were held open by gluing the lower eyelid to the skin below the eye.

\section{Visualisation of Fibres in the Film}

Confocal microscopy was used to visualise the portion of film thickness occupied by fibres. Three additional rats

Table I. Species examined using interferometry and confocal microscopy

\begin{tabular}{|c|c|c|c|c|}
\hline Species & Number & Weight & Age & Preparation \\
\hline New Zealand white rabbit (Oryctalagus cunniculus) & 8 & $3.8-5.8 \mathrm{~kg}$ & $12-16$ weeks & (a) \\
\hline Wistar rat (Rattus norvegicus) & 8 & $220-350 \mathrm{~g}$ & $8-14$ weeks & (b) \\
\hline Pigeon (Columba livia) & 6 & $320-520 \mathrm{~g}$ & 1 year & (b) \\
\hline
\end{tabular}

(a) Animals killed by intravenous pentobarbitone $150 \mathrm{mg} / \mathrm{kg}$.

(b) Animals killed by cervical dislocation. 


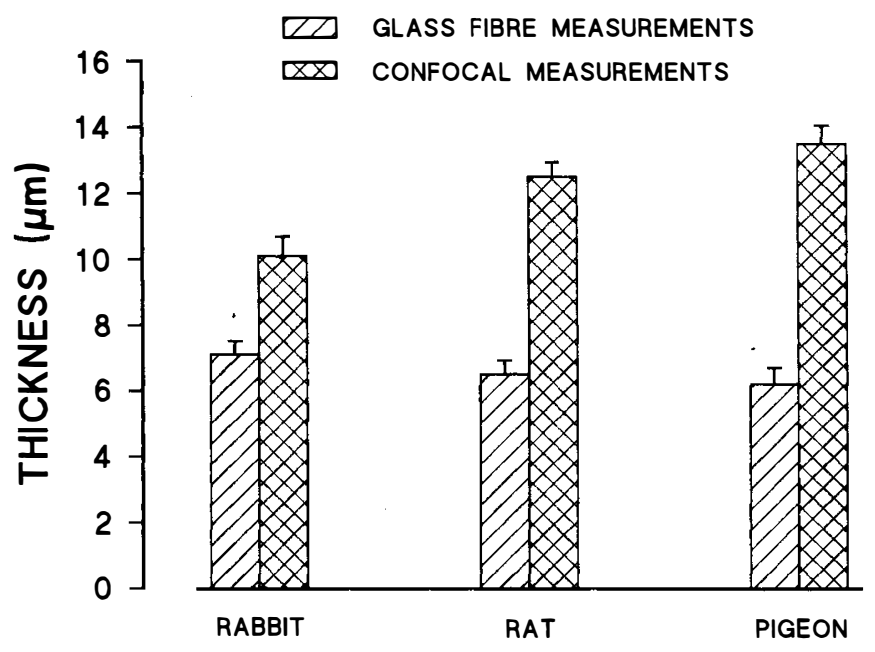

Fig. 1. Measurements of tear film thickness using confocal microscopy and the glass fibre technique in three species. Mean values in each species are plotted. Error bars are 95\% confidence limits above the mean.

were examined. A fibre which appeared level with the film surface was selected and left in position on the eye during examination by confocal microscopy.

Glass beads were also used in place of fibres. Several beads, from a mixture with diameters 5-20 $\mu \mathrm{m}$ (Polysciences), were distributed onto eyes before examination by microscopy.

Experiments were done at room temperatures of 21$27^{\circ} \mathrm{C}$ and relative humidities $48-69 \%$. Student's $t$-test was used to test statistical significance at the $95 \%$ level. Confidence limits were calculated at $95 \%$.

\section{RESULTS}

\section{Measurements Using Glass Fibres and Confocal Microscopy}

Results for each species are plotted in Fig. 1. The mean measurement in rabbits using glass fibres was $7.1 \mu \mathrm{m}$ (confidence interval $\pm 0.91 \mu \mathrm{m}$ ). Mishima ${ }^{3}$ reported a value of about $7.5 \mu \mathrm{m}$. There was no significant difference between measurements with glass fibres in the three species. Mean thicknesses in each species determined by confocal microscopy were 3-7 $\mu \mathrm{m}$ larger than those using glass fibres - a statistically larger value in every case. Confocal measurements were not significantly different from earlier measurements by this method in each species. ${ }^{2}$

Measurements with glass fibres left a dent in the film surface. It slowly flattened out over 5-10 seconds, although occasionally persisted for up to 30 seconds. A similar phenomenon was reported earlier in human eyes. ${ }^{12}$

\section{Visualisation of Fibres in the Film}

The position of fibres relative to tear and epithelial surfaces was clear. However, the glass fibre technique required that fibres were tangential to the eye surface at the position along its length where measurements were made. The confocal field of view was too small $(165 \times 125 \mu \mathrm{m})$ to see whether this was the case. Also manipulation of eyes and fibres into good positions was difficult. To obtain cross-sections through a fibre it would have had to be nearly vertical, and there was insufficient space between eye and objective for this to be possible. Thus visualisation of fibres in the film did not provide useful information.

An attempt to overcome these problems was made using glass beads in place of fibres. Several beads of different sizes were distributed onto eyes before examination by microscopy, but they formed into clumps on the film surface, so that this approach was not usable.

\section{DISCUSSION}

Measurements in rabbit eyes using glass fibres were close to those reported by Mishima ${ }^{3}$ in this species. His findings were clearly replicated. However, this method gave the same value in all species. Our optical measurements gave a range of values and thus were quite different. The glass fibre method did not correlate with full film thickness as measured by confocal microscopy. Measurements by microscopy required a correction for the difference in refractive index of tear fluid and calibration materials. However, the range of possible values was small (1.333$1.459)^{2}$ and could not have accounted for significantly different results from those presented.

Measurements using glass fibres did not seem to include the full portion of the film containing mucus, although our methods did not provide direct information about the identity of the layer measured. It was possible that fibres only measured a superficial aqueous phase, without significantly deforming underlying mucus. However, mucus is a sponge-like material with fluid in a meshwork of glycoprotein molecules. ${ }^{12}$ Fibres may have indented such a layer, expressed fluid and increased, or even created, an apparent mucus-free aqueous space as an artefact, although there was no clear evidence of this.

It is also possible that mucus is present throughout the film with no distinct free aqueous layer. Concentration of mucus may decrease from epithelial to external tear surfaces, as proposed by Holly, ${ }^{16}$ or more dilute mucus may form a distinct middle layer, as suggested by Iwata ${ }^{17}$ and by Wright and Mackie. ${ }^{18}$ The lacrimal gland may secrete mucus as well as aqueous fluid. ${ }^{13}$ Mucus from the eye and other sites is known to be viscoelastic ${ }^{14,15}$ and there seems to be a viscoelastic component at the film surface, as inferred from the observation of a dent left by glass fibres pressed against it. This may not have been appreciated before and the underestimate by glass fibres, and uniformity of measurements in all species, may have been related to these properties. Fibres appeared to be sufficiently stiff to deform such a layer, but too flexible to be pressed more than about $7 \mu \mathrm{m}$ into it.

Key words: Confocal microscopy, Glass fibre, Mucus, Tear film.

\section{REFERENCES}

1. Prydal JI, Artal P, Woon H, Campbell FW. Study of human tear film thickness using laser interferometry. Invest Ophthalmol Vis Sci 1992;33:2006-11.

2. Prydal JI, Campbell FW. Study of tear film thickness and 
structure by interferometry and confocal microscopy. Invest Ophthalmol Vis Sci 1992;33:1996-2005.

3. Mishima S. Some physiological aspects of the precorneal tear film. Arch Ophthalmol 1965;73:233-41.

4. Ehlers N. The thickness of the precorneal tear film. Acta Ophthalmol 1965 (Suppl 181) 8:92-108.

5. Benedetto DA, Shah DO, Kaufman HE. The instilled fluid dynamics and surface chemistry of polymers in the preocular tear film. Invest Ophthalmol Vis Sci 1975;14: 887-902.

6. Wolff E. The muco-cutaneous junction of the lid-margin and the distribution of the tear fluid. Trans Ophthalmol Soc UK 1946;66:291-308.

7. McDonald JE. Surface phenomena of the tear film. Am J Ophthalmol 1969;67:56-64.

8. Nichols BA, Chiappino ML, Dawson CR. Demonstration of the mucus layer of the tear film by electron microscopy. Invest Ophthalmol Vis Sci 1985;26:464-73.

9. Petran M, Hadravsky M, Benes J, Kucera R, Boyde A. The tandem scanning reflected light microscope. Proc R Microsc Soc 1985;20:125-39.

10. Xiao GQ, Kino GS, Masters BR. Observation of the rabbit cornea and lens with a new real-time confocal scanning optical microscope. Scanning 1990;12:161-6.

11. von Röth A. Über die Tränenflüssigkeit. Klin Monatsbl Augenheilkd 1922;68:598-604.

12. Odeblad EE. Nuclear magnetic resonance. In: Braga PC, Allegra L, editors. Methods in bronchial mucology. New York: Raven Press, 1988:105-23.

13. Allen M, Wright $P$, Reid L. The human lacrimal gland: a histochemical and organ culture study of the secretory cells. Arch Ophthalmol 1972;88:493-7.

14. King M. Magnetic microrheometer. In: Braga PC, Allegra L, editors. Methods in bronchial mucology. New York: Raven Press, 1988:73-83.

15. Kaura R, Tiffany JM. The role of mucous glycoproteins in the tear film. In: Holly FJ, editor. The precorneal tear film. Lubbock, Texas: Dry Eye Institute, 1986:728-32.

16. Holy FJ. Formation and rupture of the tear film. Exp Eye Res 1973;5:515-24.

17. Iwata S. Chemical composition of the aqueous phase. Int Ophthalmol Clin 1973;13:29-45.

18. Wright P, Mackie IA. Mucus in the healthy and diseased eye. Trans Ophthalmol Soc UK 1977;97:1-7. 